\section{Multi-User Scanning Electron Microscope}

L.S. Chumbley, M. Meyer, K. Fredrickson, F. Laabs*

lowa State University, *Ames Laboratory

Teaching a large number of students simultaneously to use a scanning electron microscope (SEM) has traditionally been difficult. A typical classroom scenario would be of one student seated in front of the SEM next to the instructor while the remaining students stand idly behind the operating student. The truth of the oft repeated sentiment expressed by microscopists, "There is nothing more boring than watching someone else do microscopy", would be proven time and time again in such training sessions as the uninvolved
students would quickly lose interest and either fall asleep or talk among themselves.

In order to increase student interest and involvement in microscopy, a new SEM laboratory has been developed that applies desktop computer hardware and software technology to improve the way in which SEM is taught allowing them to view images and examine samples without leaving their work to students. An interactive microscopy laboratory consisting of an SEM areas. Such an arrangement will speed information transfer and increase networked to a series of computer-based workstations has been developed at productivity. Thus, a mult-user SEM that is user friendly and relatively lowa State University. The network provides students with direct, interactive inexpensive to install and operate could have a significant impact on the use of access to the SEM. The system is currently being tested in the classroom and microscopy in education, research, and industry.

results thus far have been encouraging and the students appear enthusiastic

A photograph of the classroom is shown (Fig. 1). The classroom consists of four workstations networked to a JEOL 6100 SEM. Each station is equipped part of their Instrumentation and Laboratory Improvement Program. The SEM was with a TV monitor, a thermal printer, a joystick, and a computer, with additional acquired on a project funded by the Office of Naval Research, Mufit Akinc being space provided for textbooks and notebooks. Apple Macintosh computers the Principal Investigator. Additional funding for computer programming has been allow the students access to all controls, functions, and features of the SEM received from Engineering Computer Support Services of lowa State.

made available by the manufacturer using software developed at lowa State. In addition, image analysis and $x$-ray EDS data analysis software is available at each workstation. The microscope image is carried to the TV monitor at each remote station using the video feed provided by the manufacturers. The JEOL 6100 comes with a motorized stage as standard equipment and the circuitry was altered to include a switcher box and a series of additional

\section{COST-EFFECTIVE EM MAGNETIC SHIELDING!}

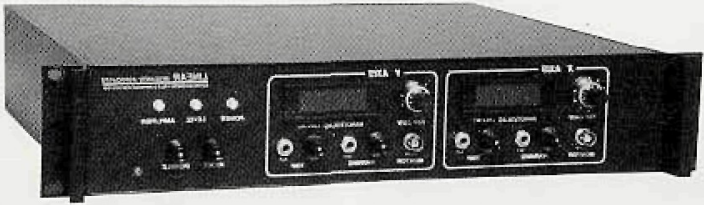

\section{LINEAR RESEARCH ASSOCIATES' active-} shielding systems dramatically improve EM performance at sites affected by magnetic fields from a.c. power wiring, ground loops, distribution transformers and related sources. Call or fax LRA for a complete description of our EMC/EMFC-series wideband a.c. magnetic field compensation systems. We also provide magnetic field survey advice and related engineering services upon request. LIN $\boldsymbol{E} \boldsymbol{A} \boldsymbol{R}$ RESEARCH ASSOCIATES 5244 PERRY CITY ROAD - TRUMANSBURG, NY 14886 (607)387-3411 - FAX (607)387.7806 joysticks. By means of the switcher box the instructor can give each remote station control of $x-y$ sample movement and rotation. The thermal printer allows students to obtain a micrograph at any time. The SEM room also contains a projection system that allows the SEM and computer screens to be displayed on a large screen for teaching purposes. The instructor can choose which display to

suitable for undergraduate and graduate classroom instruction, it is evident that possible applications of the basic operating principles of such a network exist in microscope might be established in a research facility. A technician would be responsible for inserting the sample into the microscope and aligning it while individual researchers could perform the actual investigations from the comfort of their offices using desktop computers. Similarly in an industrial setting, production and quality control personnel could be linked directly to the company SEM facility,

Funding for this project was provided by the National Science Foundation as

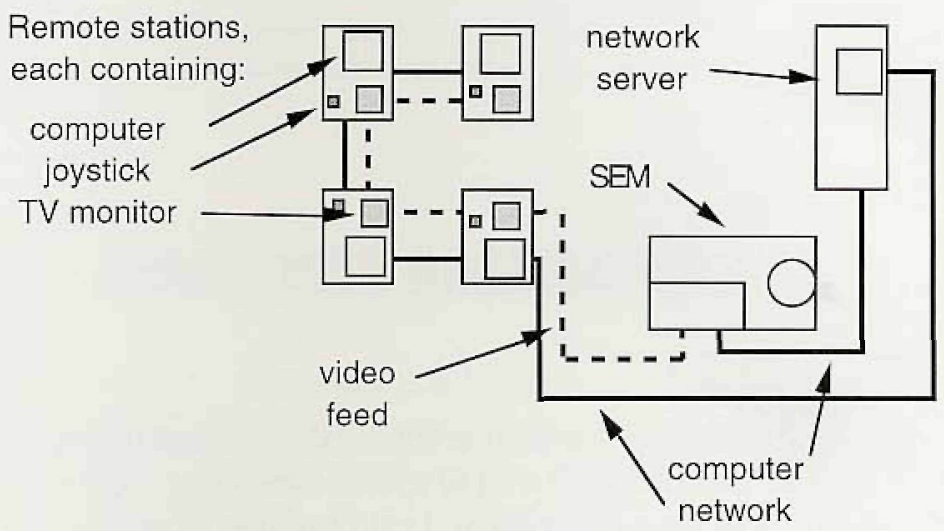

Figure 1. A schematic diagram showing the layout of the teaching classroom.

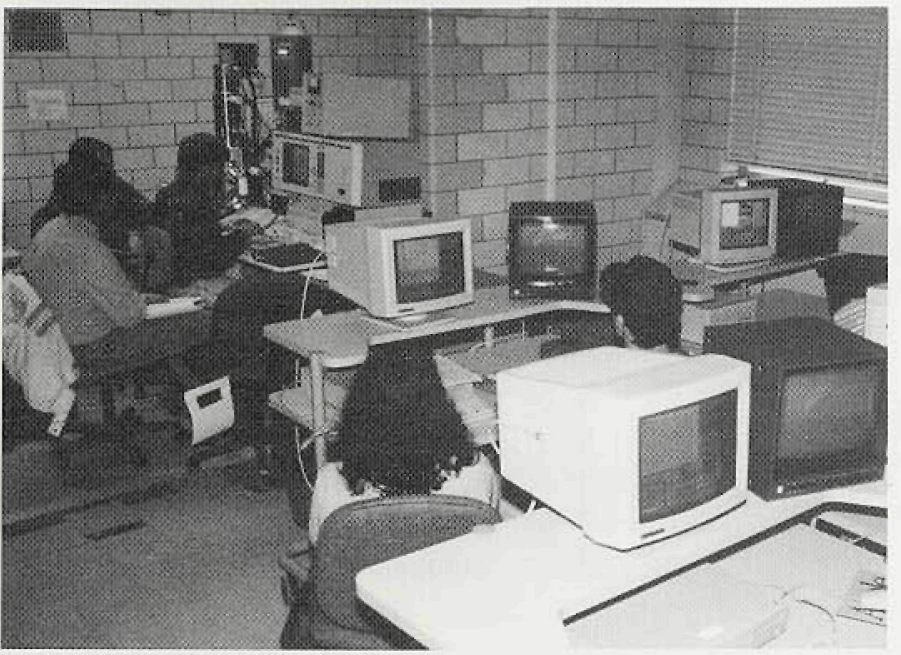

Figure 2. Photograph of the classroom in operation. The microscope can be seen in the background with the teaching stations in the foreground. Note that this picture was taken before additional joystick controls were provided to the teaching stations. 


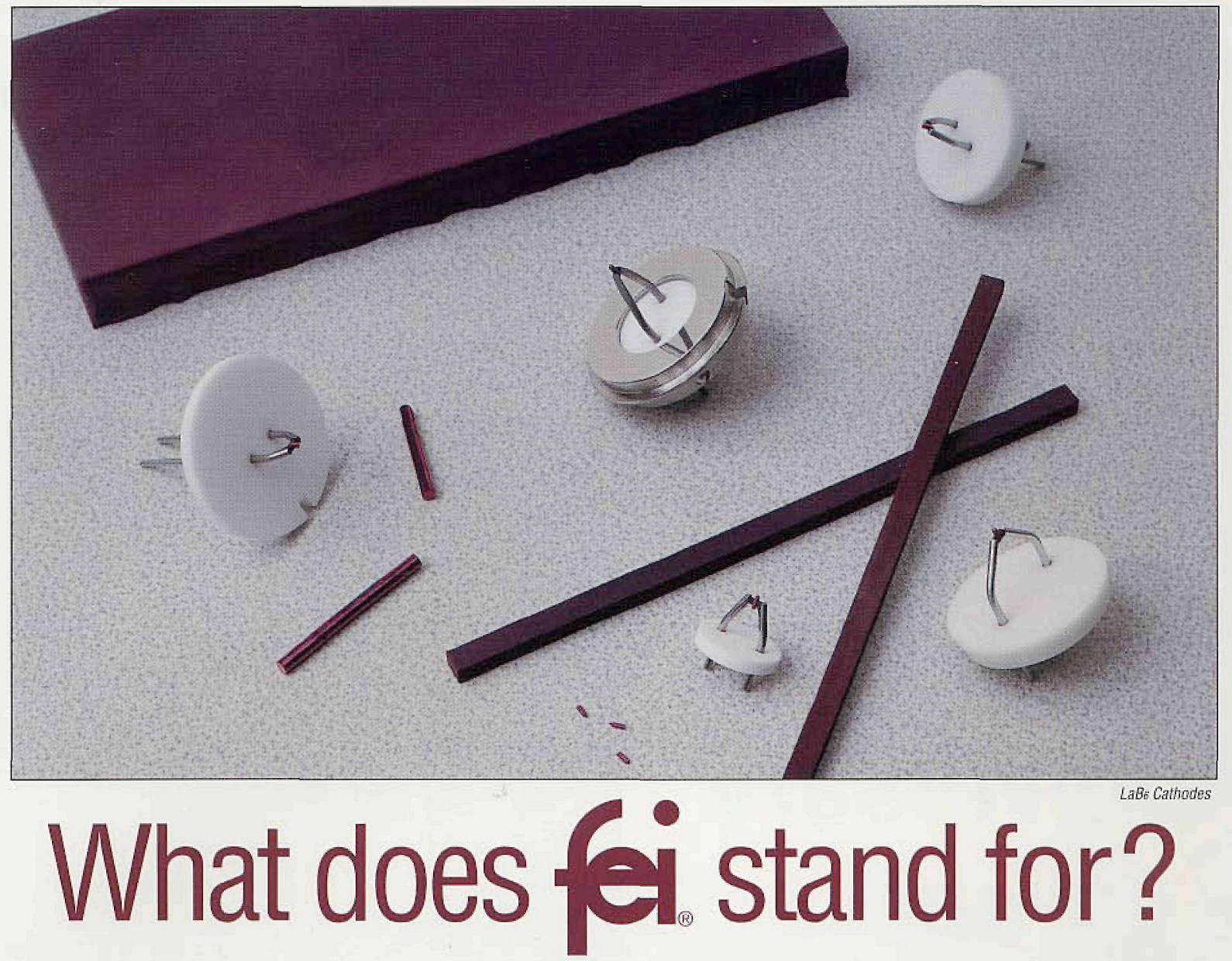

FEl's Mini Vogel Mount was the first true long-life, high stability LaB6 cathode for all electron beam instruments. The MVM is the economical emitter choice, providing consistent high quality performance and the best cost-per-use value. FEl is the innovator in the application of field emission technology...

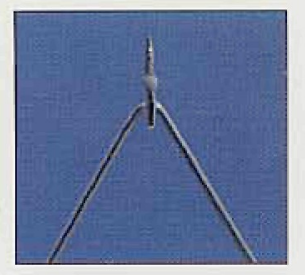

Field Emission Cathodes

FEI supplies Schottky field emitters to EM manufacturers worldwide. Schottky emission's high current intensity has established it as the preferred electron source for high resolution SEM, TEM, Auger, ESCA, EDX, and lithography.

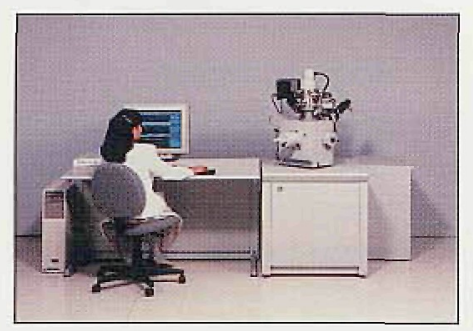

\section{FIB Workstations}

Focused ion beam micromilling workstations range from the 8"-wafer compatible model to the economical 2" small sample model ideal for semiconductor, biological, TEM, and MEMS specimens.

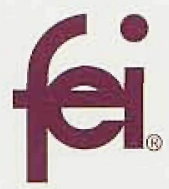

FEI Company

7451 NE Evergreen Parkway

Hillsboro, OR $97124-5830$

(503) 640-7500 Fax (503) 640-7509

email:dlh@feico.com

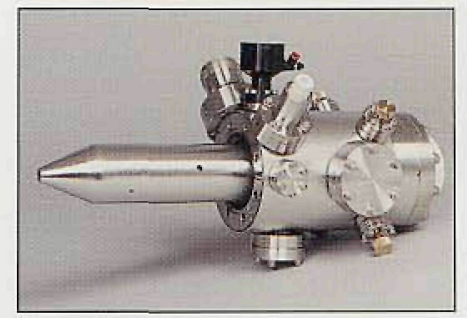

UHV Electron and Ion Columns FEl's high current density, UHV field emission focusing columns easily install on existing SIMS, Auger, and SEM instruments. 


\section{Lehigh Microscopy Courses SEM, X-ray Analysis, AEM, AFM}

\section{for Materials Engineers, Geologists, Biologists, Polymer Scientists}

\section{5th}

Anniversary Year

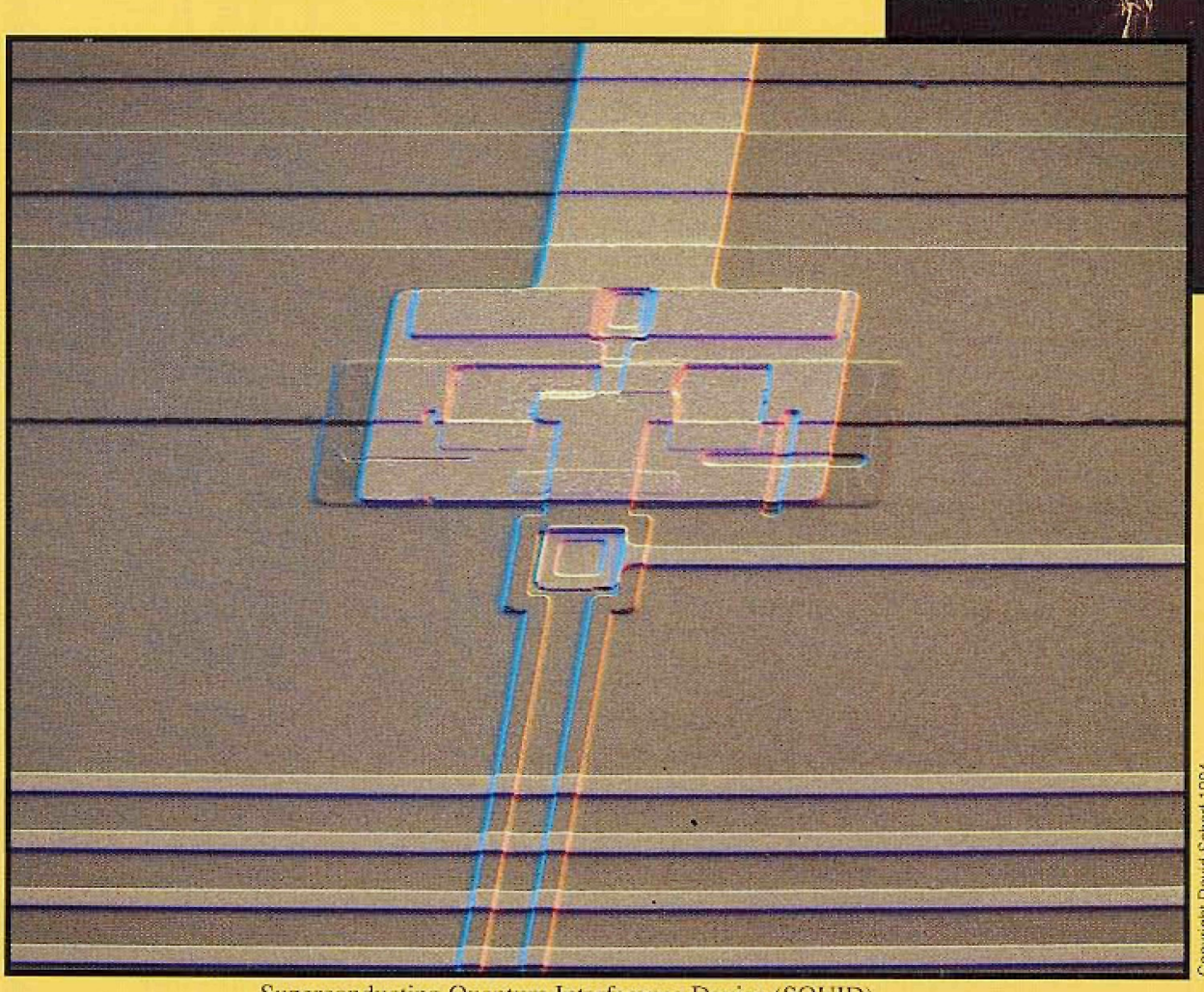

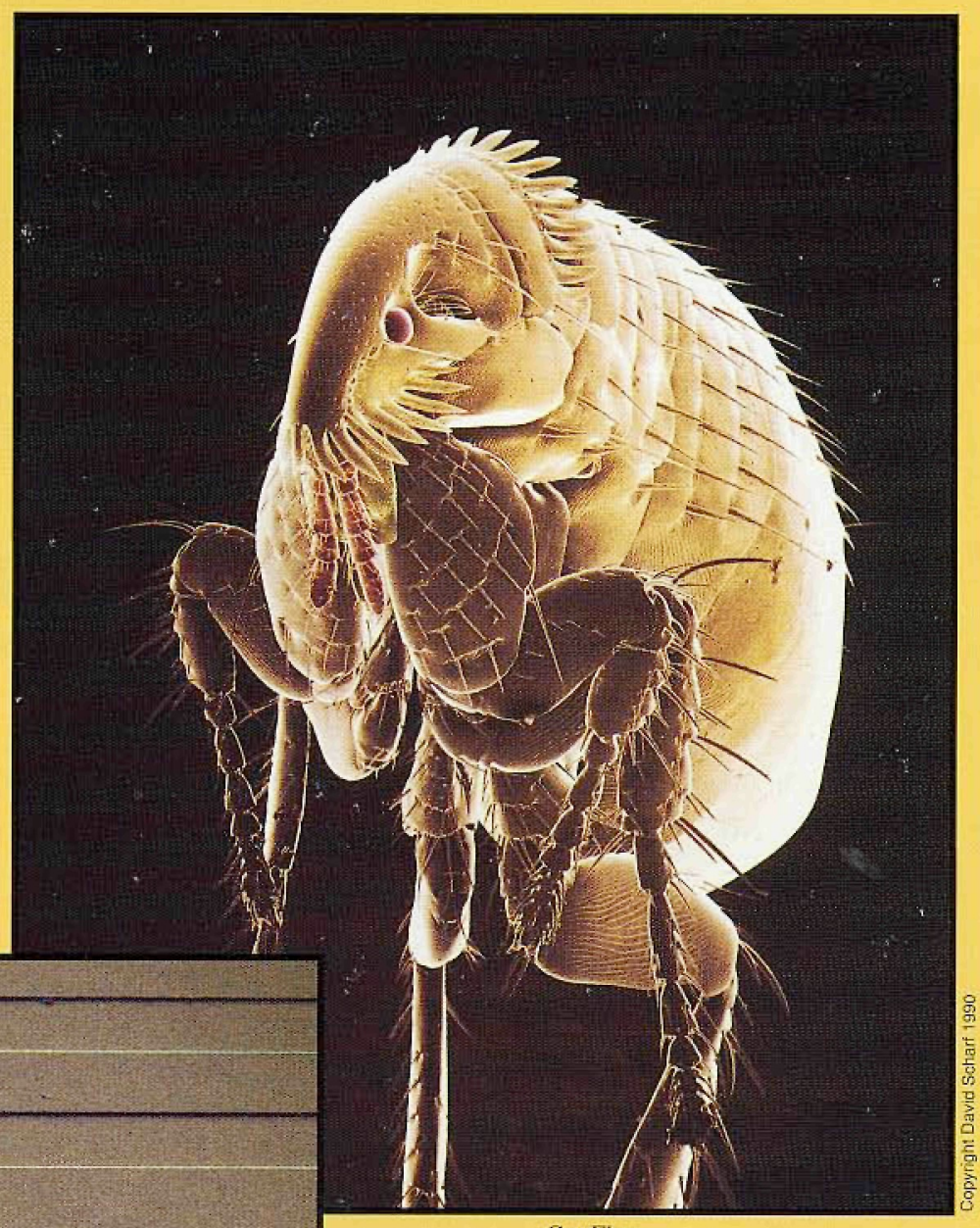

Cat Flea

For a detailed brochure contact

Sharon L. Coe

Materials Science Department

Lehigh University

5 East Packer Avenue

Bethlehem, PA 18015

Phone: 610-758-5133

e-mail: interSEM@lehigh.edu

fax: $\quad 610-758-4244$ 


\section{Scanning Electron Microscopy and X-ray Microanalysis}

\section{The Lehigh Basic Course}

(June 12-16, 1995)

For scientists, technicians, engineers, and technical managers. June 1995 marks the 25 th year of this course. Write for a brochure describing the special offer this year for offspring of past registrants.

Topics include: Image formation, optimizing SEM parameters under operator control, high resolution SEM, x-ray detectors, qualitative and quantitative $x$-ray analysis, image display and processing.

Materials topics include SEM of electronic materials, polymers and fibers, and fractography.

Biological topics include low temperature specimen preparation and immunocytochemical methods.

Instrumentation: 10 electron beam instruments with EDS, WDS, and digital imaging systems.

Textbooks Provided: Both texts were written by the course lecturers:

Scanning Electron Microscopy and X-ray Microanalysis, Plenum Press, 1992

SEM, X-ray Microanalysis, and AEM: A Laboratory Workbook, Plenum Press, 1990

\section{New for 1995}

\section{Advanced Scanning Electron Microscopy with Digital Image Processing \\ (June 19-22, 1995)}

Advanced treatment of high resolution SEM - low voltage SEM • environmental SEM • digital image acquisition - Monte Carlo simulations of electron beam-specimen interactions • electron detectors • quantitative stereo microscopy $\bullet$ stereology $\bullet$ image processing with personal computers

\section{Quantitative X-ray Microanalysis}

\section{of Bulk Specimens and Particles}

(June 19-22, 1995)

Advanced topics include: ZAF and $\phi(\rho z)$ calculations using personal computers $\cdot$ WDS and EDS detectors • quantitative analysis of thin particles and rough specimens • light element analysis • trace element analysis • strategies for applying microanalysis techniques $\bullet$ specimen preparation

\section{Analytical Electron Microscopy}

\section{and Quantitative Analysis of Thin Specimens}

(June 19-22, 1995)

Advanced topics include: TEM/STEM and dedicated STEM instruments $\cdot Z$-contrast $\bullet x$-ray microanalysis • electron energy loss spectrometry $\bullet$ quantitative analysis $\bullet$ compositional imaging • convergent beam electron diffraction - microcomputer calculations $\bullet$ thin specimen preparation

\section{Atomic Force Microscopy}

\section{and Other Scanned Probe Microscopies}

(June 20-23, 1995)

Atomic force microscopy • scanning tunneling microscopy • scanning tunneling spectroscopy • feedback control • tip fabrication - tip-sample interactions • scan calibrations • in-situ imaging • UHV imaging • imaging in air and liquids $\bullet$ image processing $\bullet$ near-field optical probes $\bullet$ metrology $•$ lateral force microscopy • electrochemical STM/AFM • other emerging scanned probe techniques 